This item was submitted to Loughborough's Research Repository by the author.

Items in Figshare are protected by copyright, with all rights reserved, unless otherwise indicated.

\title{
Indicative SAR levels due to an active mobile phone in a front trouser pocket
} in proximity to common metallic objects

\section{PLEASE CITE THE PUBLISHED VERSION}

\section{PUBLISHER}

(C) Institute of Electrical and Electronics Engineers (IEEE)

\section{LICENCE}

CC BY-NC-ND 4.0

\section{REPOSITORY RECORD}

Whittow, W.G., C.J. Panagamuwa, R.M. Edwards, and Lei Ma. 2019. "Indicative SAR Levels Due to an Active Mobile Phone in a Front Trouser Pocket in Proximity to Common Metallic Objects". figshare.

https://hdl.handle.net/2134/3340. 
This item was submitted to Loughborough's Institutional Repository by the author and is made available under the following Creative Commons Licence conditions.

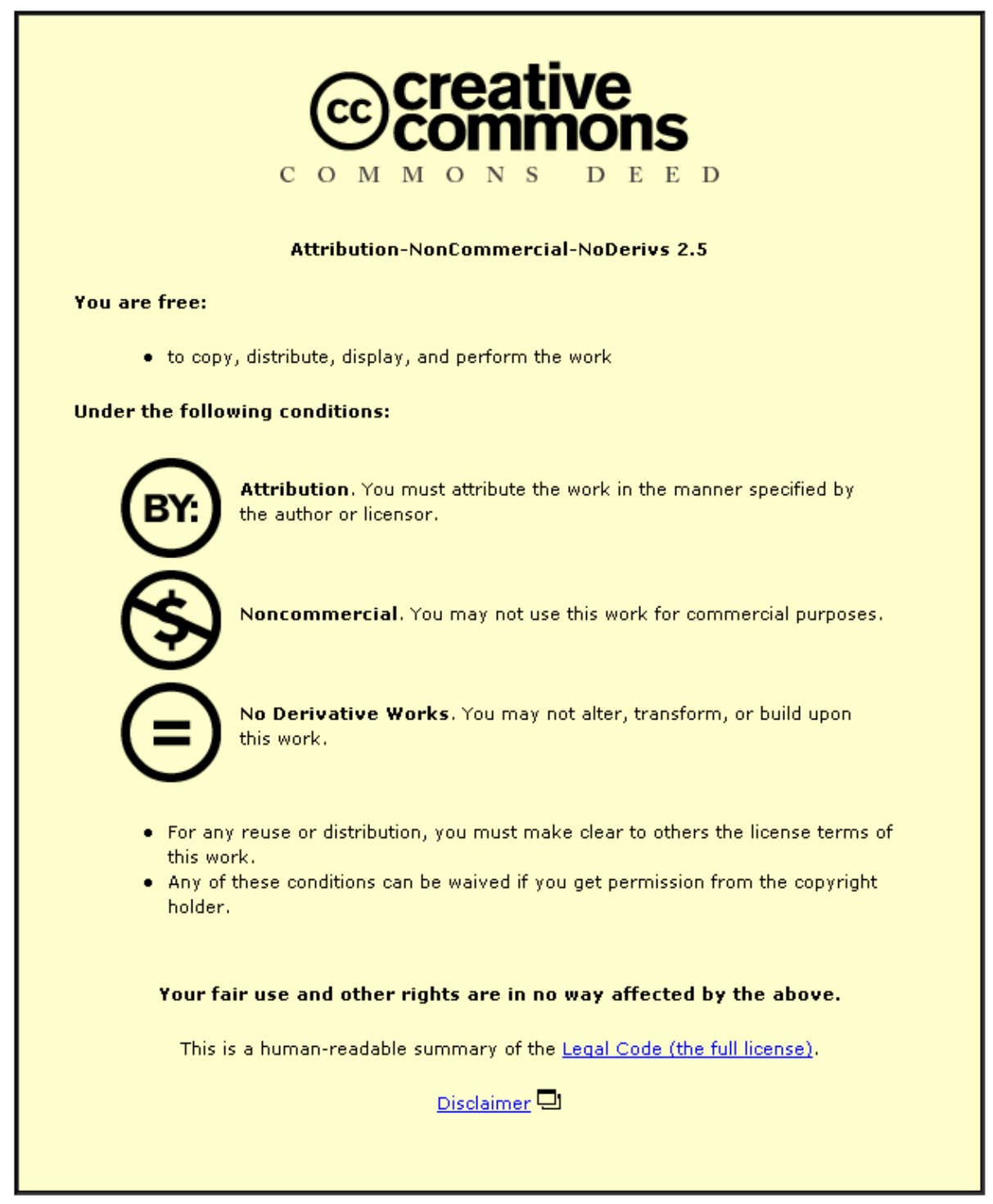

For the full text of this licence, please go to: http://creativecommons.org/licenses/by-nc-nd/2.5/ 


\title{
INDICATIVE SAR LEVELS DUE TO AN ACTIVE MOBILE PHONE IN A FRONT TROUSER POCKET IN PROXIMITY TO COMMON METALLIC OBJECTS
}

\author{
W. G. Whittow (1), C. J. Panagamuwa (1), R. M. Edwards (1) and L. Ma (1) \\ (1) Department of Electronic \& Electrical Engineering, Loughborough University, \\ Leicestershire, LE11 3TU. UK. \\ Email:W.G.Whittow@lboro.ac.u; Email: C.J.Panagamuwa@lboro.ac.uk \\ Email: R.M.Edwards@lboro.ac.uk
}

\begin{abstract}
This paper investigates Specific Absorption Rates (SAR) in the human body with a realistic mobile phone source positioned in a 'front trouser pocket' of a truncated male heterogeneous anatomical body model. A Finite-Difference Time-Domain (FDTD) code was used to analyse the SAR in the body in the mobile communication frequency range 0.9 to $4 \mathrm{GHz}$. Realistic everyday metallic objects, including a coin, a ring and a zip were added to the model. These objects increased the SAR in the body at different frequencies. The cumulative effect of the three objects generally increased the SAR in the waist section over the frequency range considered.
\end{abstract}

\section{Introduction}

There has been public and scientific comment that the radiation from mobile communications devices may adversely affect human health. Recent estimates suggest there are 40 million mobile phones users in the UK. Mobile phones spend the majority of their time in a trouser pocket and are therefore in close proximity to the testicles. Even when not in use, mobile phones emit radiation periodically as they communicate their position with base stations. Mobile phones are also left in the pocket when used with a hands-free device whether it is via a wire or a Bluetooth link. In many systems, in order to conserve battery life, a phone's power level may be dynamically negotiated with a base station to be at a minimum level whilst maintaining a reasonable signal to noise ratio. However, since a phone in a pocket is generally less efficient than a phone held to the ear, the average power from the phone may in some circumstances be higher. Note, neither the wire of a hands-free microphone or additional $\mathrm{CW}$ source for a Bluetooth link are considered in this paper.

A survey of 419 people showed that $57 \%$ of men put their mobile phone in their trouser pocket [1] with an additional $15 \%$ using a belt attachment, whereas $66 \%$ of women keep their phone in a bag. Men tended to put their phone in the front right pocket. This was particularly true for men under 30 .

A mobile phone located on the belt and used with a hands-free wire has been reported at $1.8 \mathrm{GHz}$ [2]. That paper used a $5 \mathrm{~mm}$ resolution cell size and concentrated on the efficiency of the phone and the maximum SAR. The SAR in the body and the testicles has been investigated with different sources including a dipole near the torso and a WLAN card on a laptop computer [3]. A wrist-watch type phone has also been modelled with the hands held by the waist [4]

In previous works, the authors $[5,6]$ have found that metallic objects close to the human body can significantly increase the SAR. Please see $[5,6]$ for a more complete literature review of bioelectromagnetics and the effects of metallic objects on SAR. Recently, the authors showed that metallic rings approximately one

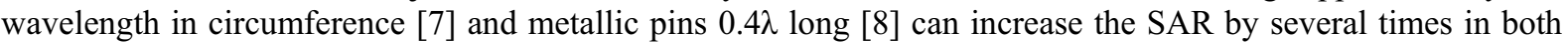
homogenous and heterogeneous heads.

We have also hypothesized that metallic objects in close proximity to the waist could increase the SAR. Typical metallic objects close to or inside a front trouser pocket may include metallic zips, coins, keys, key rings and pens. This paper will present results for a metallic coin, a ring and a zip as well as the combination of all three. The testicles are considered to be sensitive organs $[9,10]$ and are located close to the outside of the body. They are vulnerable to heating, however, [11] concluded that the testes of mice were naturally capable of regulating their temperature. In terms of size they may be similar to eyes which have been shown to resonate at some mobile phone frequencies $[5,6,12]$.

\section{Description of model}

An independent 3D FDTD code [5, 6] has been written. Perfectly Matched Layers (PML) absorbing boundary conditions are used to terminate the grid. The PML is eight cells thick and is positioned at least twelve cells from 
the source and the body. The Yee cell size used throughout this paper is $2 \mathrm{~mm}$. The lowest number of cells per wavelength was always greater than five, and reasonable results have been obtained with only four [2].

The excitation in this paper was a monopole positioned at the centre of the top face of a PEC box. The box was $80 \mathrm{~mm}$ high, $40 \mathrm{~mm}$ wide and $20 \mathrm{~mm}$ deep. The monopole was $Z$ directed and fed with a sinusoidal $\mathrm{CW}$ source. The tangential E-field components are set to zero along the length of the monopole and surface of the PEC box [5]. The box was surrounded with a layer of plastic $2 \mathrm{~mm}$ thick $\left(\sigma=0 \mathrm{~S} / \mathrm{m}, \varepsilon_{r}=2.56\right)$ with a $2 \mathrm{~mm}$ gap surrounding the excitation location. All results in this paper are normalised to $1 \mathrm{~W}$ input power at all frequencies. Please note that an output power of $1 \mathrm{~W}$ may be higher than for many mobile phones. However the results in this paper may be scaled. The SAR is calculated with the twelve-field approach [5]. The geometry and location of the phone are shown in Figure 1.

An anatomically accurate human body model provided by Brooks Air Force was used. The body phantom used is based on the Visible Human Project, has 40 tissues and a $2 \mathrm{~mm}$ resolution. To reduce the considerable runtimes and excessive memory requirements, the body was truncated in the $\mathrm{Z}$ direction, so that only the waist was modelled; see Figure 1 (a). This truncated section of the body contained 19 different tissues.

In this model, the testicles have a density of $1040 \mathrm{~kg} / \mathrm{m}^{3}$ and a combined mass of $22.85 \mathrm{~g}$. The tissues are frequency dependent [13]. The testicles have the following electrical properties: $\left(\sigma=1.06 \mathrm{~S} / \mathrm{m}, \varepsilon_{r}=62.45\right.$ at $0.5 \mathrm{GHz} ; \sigma=1.69 \mathrm{~S} / \mathrm{m}, \varepsilon r=58.61$ at $1.8 \mathrm{GHz} ; \sigma=3.68 \mathrm{~S} / \mathrm{m}, \varepsilon r=55.13$ at $5 \mathrm{GHz}$ ). Therefore, energy absorption is more superficial at higher frequencies where not only is the wavelength reduced but the conductivity is higher.

The metallic objects were modelled using metallic Yee cells, by setting the conductivity of the cells equal to the conductivity of copper [5] and were $2 \mathrm{~mm}$ thick ( 1 Yee cell). The metallic zip was $142 \mathrm{~mm}$ long and $6 \mathrm{~mm}$ wide. The coin had a diameter of $20 \mathrm{~mm}$ and was $2 \mathrm{~mm}$ thick and was positioned in the XY plane level with the base of the phone. The ring had a diameter of $20 \mathrm{~mm}$, was $2 \mathrm{~mm}$ thick and was positioned between the phone and the body. Please see Figure 1 for the exact locations of the metallic objects.

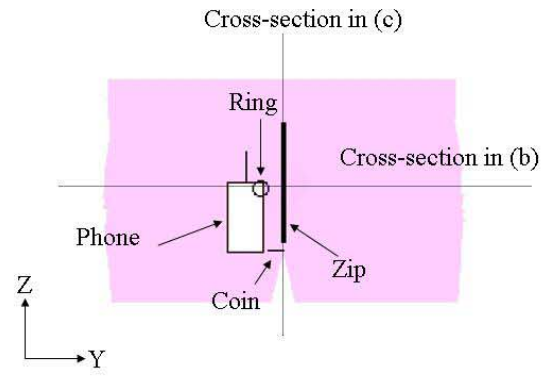

(a) Truncated Brooks body

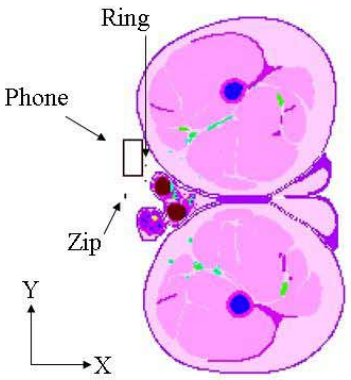

(b) Cross-section in XY plane

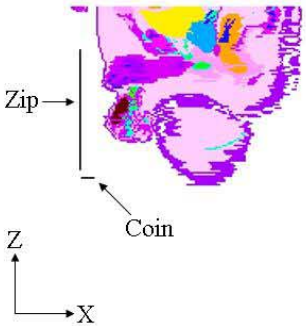

(c) Cross-section in $\mathrm{XZ}$ plane

Figure 1. The geometry of the Brooks waist: (a) truncated Brooks body with phone as seen from the front, (b) and (c) show two cross-sections through the model.

\section{Results}

The maximum 10g SAR values in all tissues in the waist section are shown in Figure 2. The coin has negligible effect below $2.8 \mathrm{GHz}$ and a small effect upto $4 \mathrm{GHz}$. The zip increased the $10 \mathrm{~g}$ SAR at approximately 2 and 3.3GHz. The ring increased the SAR at all frequencies considered below $3.9 \mathrm{GHz}$. However, the largest effect was found when all three metallic objects were added to the Brooks waist. The combination of zip, coin and ring increased the $10 \mathrm{~g}$ SAR between 1 and $4 \mathrm{GHz}$. The $10 \mathrm{~g}$ SAR was nearly doubled at $1.8 \mathrm{GHz}$ and $3.2 \mathrm{GHz}$. The increase in SAR due to the three objects was roughly but not exactly related to the increase in SAR of the three objects when considered individually. The $1 \mathrm{~g}$ SAR values in all tissues had a similar shape to the $10 \mathrm{~g}$ SAR values, except the $1 \mathrm{~g}$ SAR values were approximately 3 times higher.

The average SAR in the (right) testicle closest to the phone was also considered and the results are shown in Figure 3. The testicle in the model, without metallic objects, showed a slight resonance at 1.1GHz. The average SAR in the left testicle, which has a similar mass but a different shape, decreased with frequency. Hirata [12] showed that eyes of different sizes resonated at different frequencies, so different models or people may be different. Adding metallic objects produced similar results to the SAR in the right testicle as to the $10 \mathrm{~g}$ SAR. Above $1.1 \mathrm{GHz}$, the addition of all three objects increased the SAR averaged over the testicle. At $0.9 \mathrm{GHz}$, the three objects significantly reduced the SAR in the testicle. At $1.8 \mathrm{GHz}$ the average SAR was increased by $70 \%$. Note the right testicle has a mass of 11.63g and is comparable with the 10g SAR results in Figure 2. Above 
$1.1 \mathrm{GHz}$, the average SAR value in the right testicle was less than the maximum $10 \mathrm{~g}$ SAR as the maximum $10 \mathrm{~g}$ SAR occurred in the leg which was closer to the source.

The maximum $1 \mathrm{~g}$ SAR in the testicles was also considered and the results, shown in Figure 4, were found to be similar to the average SAR in the right testicle shown in Figure 3, except the 1g SAR results were roughly twice as large. The smaller $1 \mathrm{~g}$ SAR volume had a larger effect at around $3.3 \mathrm{GHz}$, where the energy absorption is more superficial. The $1 \mathrm{~g}$ SAR values in the testicles were approximately half the $1 \mathrm{~g}$ SAR values in all tissues.

\section{Conclusions}

The FDTD method was used to investigate the SAR in the waist section of the human body. Realistic metallic objects added in close proximity to the model both increased and decreased the SAR. When all three objects were added, the SAR in both the leg and in the testicles was generally increased and approximately doubled at $1.8 \mathrm{GHz}$. The addition of extra metallic objects was roughly cumulative but not exactly. This shows that the system is more complicated with multiple objects interacting with each other. Note, that the location of the phone and metallic objects was arbitrarily chosen and based on realistic sizes. No attempt was made to find the worst case scenario or to choose a range of objects that resonate at the same frequency. The testicle closest to the phone showed a slight resonance but the SAR values were generally lower than in the leg. However, it is hypothesized that lower SAR levels in the testicles could be more concerning than the same values in the leg.

\section{References}

[1] F. Ichikawa, J. Chipchase, and R. Grignani, "Where's The Phone? A Study of Mobile Phone Location in Public Spaces," in Mobile Technology, Applications and Systems, 2005 2nd International Conference on, 2005, pp. 1-8.

[2] S. E. Troulis, W. G. Scanlon, and N. E. Evans, "Effect of a hands-free wire on specific absorption rate for a waist-mounted 1.8 GHz cellular telephone handset," Physics in Medicine and Biology, vol. 48, pp. 1675-1684, 2003.

[3] A. Christ, T. Samaras, E. Neufeld, A. Klingenböck, and N. Kuster, "SAR distribution in human beings when using body-worn RF transmitters," Radiat Prot Dosimetry vol. 124, pp. 6-14, 2007.

[4] M. Park, C. Ko, and J. Pack, "Analysis of SAR for body-mounted mobile phones," in XXVIIIth URSI General Assembly, New Delhi, India, 23 to 29 October 2005, 2005.

[5] W. G. Whittow and R. M. Edwards, "A study of changes to specific absorption rates in the human eye close to perfectly conducting spectacles within the radio frequency range 1.5 to $3.0 \mathrm{GHz}$, IEEE Trans. Antennas and Propagation, vol. 52, pp. 3207-3212, 2004.

[6] W. G. Whittow and R. M. Edwards, "Applications of a genetic algorithm for identification of maxima in specific absorption rates in the human eye close to perfectly conducting spectacles," IEE Proceedings Science, Measurement \& Technology, vol. 152, pp. 89-96, 2005.

[7] W. Whittow, C. Panagamuwa, R. Edwards, and J. Vardaxoglou, "Specific absorption rates in the human head due to circular metallic earrings at $1800 \mathrm{MHz}$," in 2007 Loughborough Antennas and Propagation Conference, Loughborough, UK, 2007, pp. 277-280.

[8] W. Whittow, C. J. Panagamuwa, R. Edwards, J. C. Vardaxoglou, and P. McEvoy, "A study of head worn jewelry, mobile phone RF energy and the effect of differing tissue types on rates of absorption," in The First European Conference on Antennas and Propagation (EuCAP 2006), Nice, France, 2006.

[9] E. Derias, P. Stefanis, A. Drakeley, R. Gazvani, and D. Lewis-Jones, "Growing concern over the safety of using mobile phones and male fertility " Archives of Andrology, vol. 52, pp. 9-14, 2006.

[10] S. Dasdag, M. Akdag, F. Aksen, F. Yilmaz, M. Bashan, M. Dasdag, and M. Celik, "Whole body exposure of rats to microwaves emitted from a cell phone does not affect the testes," Bioelectromagnetics, vol. 24, pp. 182-188, 2003.

[11] A. B. Cairnie, D. A. Hill, and H. M. Assenheim, "Dosimetry for a study of effects of $2.45-\mathrm{GHz}$ microwaves on mouse testis," Bioelectromagnetics, vol. 1, pp. 325-336, 1980.

[12] A. Hirata, S. Matsuyama, and T. Shiozawa, "Temperature rises in the human eye exposed to EM waves in the frequency range 0.6-6 GHz," IEEE Transactions on Electromagnetic Compatibility, vol. 42, pp. 386-393, 2000.

[13] S. Gabriel, R. W. Lau, and C. Gabriel, "The dielectric properties of biological materials: III. Parametric models for the dielectric spectrum of tissues," Physics in Medicine and Biology, vol. 41, pp. 2271-2293, 1996. 


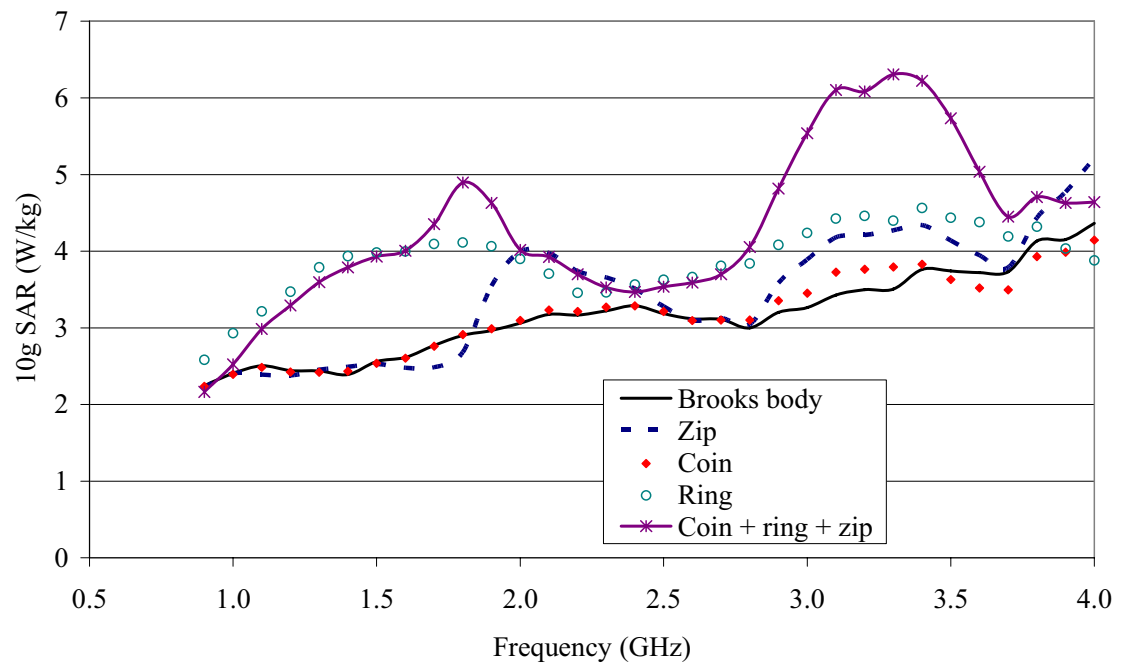

Figure 2. The 10g SAR in the Brooks waist as a function of frequency.

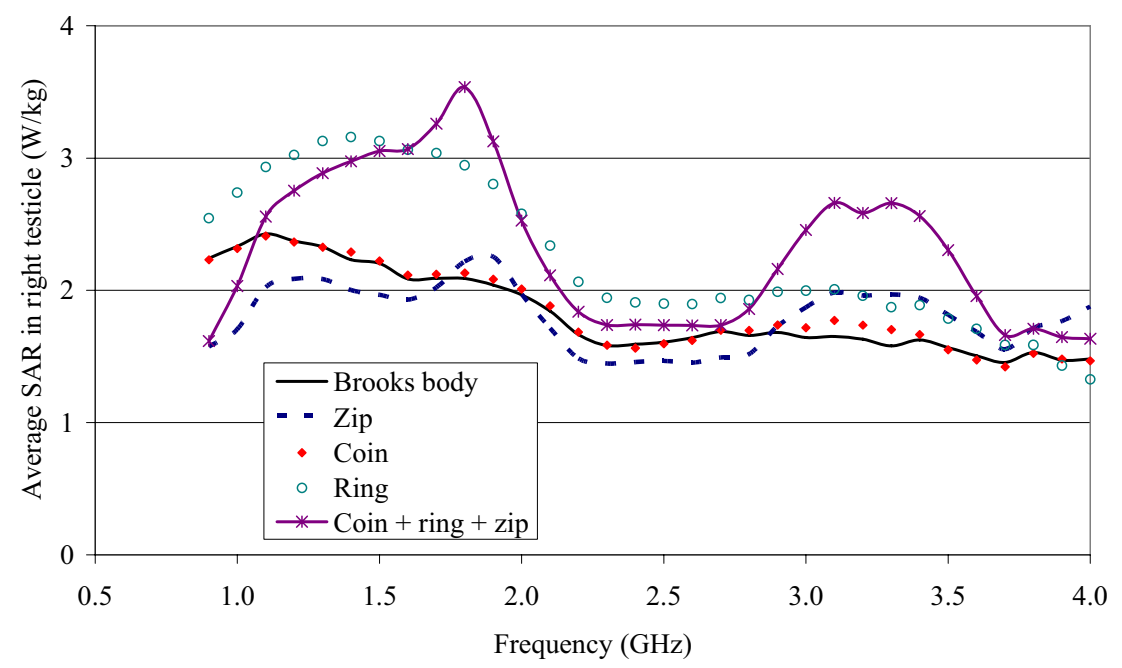

Figure 3. The average SAR in the right testicle as a function of frequency.

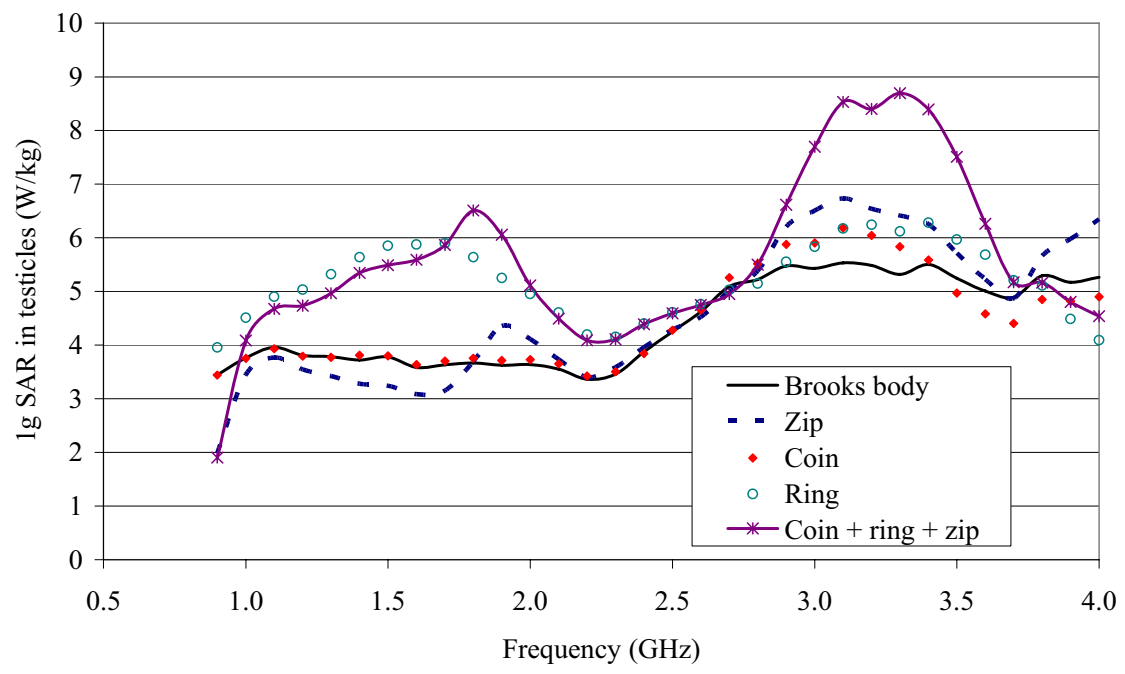

Figure 4. The maximum $1 \mathrm{~g}$ SAR in the testicles as a function of frequency. 